\title{
OPEN The association between elevated lipid profile and liver enzymes: a study on Bangladeshi adults
}

Rahanuma Raihanu Kathak, Abu Hasan Sumon, Noyan Hossain Molla, Mahmudul Hasan, Rakib Miah, Humaira Rashid Tuba, Ahsan Habib \& Nurshad Ali ${ }^{\bowtie}$

Dyslipidemia, a major contributor to cardiovascular diseases, is rapidly increasing in Asian countries including Bangladesh. In addition to the cardiovascular system, abnormal lipid levels are also known to cause complications in renal and hepatic systems. The data regarding dyslipidemia and its relationship with liver enzymes are scarce for the Bangladeshi population. Therefore, this study was conducted to estimate the prevalence of dyslipidemia and determine the relationship between lipid profile and liver enzymes in Bangladeshi adults. A total of 405 participants (318 males and 87 females) were enrolled in the study. Serum levels of TG, TC, LDL, HDL and liver enzymes including ALT, AST, GGT and ALP were analyzed using standard methods. Dyslipidemia and liver function tests abnormalities were defined according to the international standard guidelines. The association between elevated lipid profile markers and liver enzyme abnormalities was assessed by logistic regression analysis. Overall, the prevalence of elevated TG, TC, LDL and low HDL were $30.9 \%, 23.7 \%$, $26.2 \%$ and $78.8 \%$, respectively. On the other hand, the prevalence of elevated liver enzymes ALT, AST, GGT and ALP were $18.8 \%, 21.6 \%, 12.9 \%$ and $21.9 \%$, respectively. Dyslipidemia and liver enzyme abnormalities were higher in diabetic and hypertensive participants than in the healthy participants. About $61 \%$ of participants with dyslipidemia had at least one or more elevated liver enzymes. In regression analysis, an independent association was observed between serum GGT and all lipid components. In conclusion, a high prevalence of dyslipidemia and liver enzyme abnormalities were observed among the study participants. Of the four liver enzymes, the serum levels of GGT showed an independent association with all lipid components. Moreover, this study indicates that subjects with dyslipidemia often have a higher chance of having liver diseases than subjects with no dyslipidemia. However, large-scale prospective studies are needed to understand the underlying mechanisms of lipid-induced hepatic dysfunction in the Bangladeshi population.

Dyslipidemia is a major contributor to cardiovascular diseases (CVDs) and considered a global public health challeng $\mathrm{e}^{1,2}$. Research over the recent decades has reported an increased prevalence of dyslipidemia among the general population ${ }^{2}$. Moreover, an epidemiological shift of dyslipidemia has been observed in developing nations compared to the developed nations ${ }^{3}$. Studies from South Asian countries have reported an upward trend of dyslipidemia among the population living in these regions ${ }^{4-6}$.

Dyslipidemia mediated cardiovascular diseases are the leading cause of death worldwide ${ }^{7,8}$. The prevalence of CVDs is rapidly increasing in the Bangladeshi population ${ }^{9}$. Dyslipidemias are also known to cause complications in endocrine systems, central nervous system, hepatic and renal systems ${ }^{10}$. Although dyslipidemia affects the major organ systems, the liver is considered to be highly affected due to its close association in lipid metabolism. The liver plays a significant role in lipid metabolism by manufacturing, storing, and transporting lipid metabolites ${ }^{11}$. Thus, abnormality in the lipid level, can lead to a change in liver metabolism and can damage the hepatic tissue ${ }^{12}$. The most common chronic liver disease represented by excess accumulation of lipids in the liver is known as non-alcoholic fatty liver disease (NAFLD). Currently, it is the most common form of hepatic disorder in the developed nations and is predicted to be identical for developing nations in the next decades ${ }^{13,14}$. Bangladesh is also experiencing an upward trend of fatty liver diseases, with a current prevalence of NAFLD at $33.8 \%{ }^{15}$.

The liver enzymes aspartate aminotransferase (AST), alanine aminotransferase (ALT), alkaline phosphatase (ALP) and $\gamma$-glutamyltransferase (GGT) are generally applied as a good marker for assessing liver health ${ }^{16}$. Serum ALT is considered as a specific marker for hepatic damage and is mainly found in this organ ${ }^{17-19}$, while serum 
GGT is present in maximum cell surface and highly active in the kidney, liver, and pancreas ${ }^{17}$. Serum GGT is considered as a biomarker of alcohol consumption and hepatic injury ${ }^{17}$. Furthermore, GGT mediates glutathione uptake and is thought to be connected to oxidative stress and inflammation ${ }^{17,20,21}$. Increased levels of serum ALT and GGT are associated with various risk factors for metabolic syndrome, diabetes, and cardiovascular diseases such as obesity, hyperglycemia, dyslipidemia and increased blood pressure. Elevated levels of ALT and GGT have also been found to be associated with NAFLD ${ }^{22}$.

Although many studies investigated the effect of dyslipidemia on the cardiovascular system ${ }^{7,23}$, there are limited studies that have investigated the impact of dyslipidemia on liver functions. A study revealed that ALT and AST, the markers of hepatic dysfunction, are associated with elevated lipid profiles among the general population in the USA ${ }^{24}$. Despite the high occurrence of lipid-induced liver dysfunction; there are no exact statistics on the incidence of dyslipidemia and its impact on liver function in the Bangladeshi population. A few epidemiological studies reported the prevalence of dyslipidemia among the Bangladeshi adults ${ }^{25-27}$, but most of them were confined to a particular group rather than the more general population and did not consider some potential confounders, such as diabetes and hypertension. In addition, the association between lipid profile and liver enzymes has not been studied so far for Bangladeshi adults. Therefore, this study aims were to conduct a cross-sectional study to estimate the prevalence of dyslipidemia and evaluate the interrelationship between lipid profile and liver enzymes in Bangladeshi adults.

\section{Methods}

Study design and participant selection. A cross-sectional population-based study was conducted between December 2018 and February 2020 at the Department of Biochemistry and Molecular Biology, SUST, Bangladesh. In this study, a total of 405 subjects were randomly selected from general adults in the Sylhet region including academic and non-academic staff, undergraduate and graduate students. Of them, 87 were females and 318 were male subjects. Inclusion criteria: (1) both gender (18 years and above) (2) free from any severe and chronic illness and (3) willing to participate in the study. Exclusion criteria: (1) pregnant and breastfeeding women (2) participants with a present or past history of hepatotoxic drug intake, alcoholism (3) self-reported evidence of viral hepatitis and (4) subjects who did not provide blood samples or complete the questionnaire. Informed consent was obtained from all participants before their participation in the study. Ethical approval for this study was obtained from the Internal Ethics Review Board (ERB), Department of Biochemistry and Molecular Biology, School of Life Sciences, SUST (Reference number. 02/BMB/2019). All procedures of the study were carried out in accordance with relevant institutional and national guidelines and regulations.

Anthropometric measurements. Anthropometry includes measurements of body weight, height, hip circumference (HC) and waist circumference (WC) were performed following the standard procedures described elsewhere ${ }^{28-37}$. Briefly, the body weight was measured by digital weighing machines (Beurer 700, Germany) to the nearest $0.1 \mathrm{~kg}^{38}$. The standing body height (stature) was measured to the nearest $0.1 \mathrm{~cm}$ using a measuring tape. BMI was calculated as the ratio of a person's weight in kilograms $(\mathrm{kg})$ divided by the height in meters squared $\left(\mathrm{m}^{2}\right)$. The systolic (SBP) and diastolic (DBP) blood pressures were recorded by a digital BP machine (Omron, Tokyo, Japan). A mean value of two consecutive blood pressure measurements was calculated for each subject and used for the analysis.

Sample collection and biochemical analysis. About $4 \mathrm{ml}$ of fasting blood samples were collected from each participant by venipuncture using disposable needles and syringes. After centrifugation of blood samples, serum was separated and stored at $-80^{\circ} \mathrm{C}$ until biochemical parameter analysis. The serum levels of fasting blood glucose (FBG), total cholesterol (TC), triglycerides (TG), low-density lipoprotein (LDL) and high-density lipoprotein (HDL) were measured by standard colorimetric methods. The concentrations of serum alanine and aspartate aminotransferase (ALT and AST), $\gamma$-glutamyltransferase (GGT), and alkaline phosphatase (ALP) were measured by kinetic methods. The available diagnostic kits were purchased from Human Diagnostic (Germany), except GGT from Vitro Scient (Egypt) to measure the biochemical parameters ${ }^{38}$. All the biochemical analysis was done using a semi-automated biochemistry analyzer (Humalyzer 3000, USA). All the analyses were performed according to the manufacturer's instructions. The inter-laboratory precision and accuracy of all measurements were confirmed by regular calibration using reference standards provided in the kits.

Diagnostic criteria. The National Cholesterol Education Program Adult Treatment Panel III (NCEP/ATP III $)^{39}$ was followed to define dyslipidemia, as the presence of one or more measurements of TC $\geq 240 \mathrm{mg} / \mathrm{dL}$; TG: $\geq 150 \mathrm{mg} / \mathrm{dL} ; \mathrm{LDL} \geq 160 \mathrm{mg} / \mathrm{dL}$ and $\mathrm{HDL}<40 \mathrm{mg} / \mathrm{dL}$. Abnormal or elevated liver enzymes were confirmed if there were at least one or more measurements of ALT level $>45 \mathrm{U} / \mathrm{L}$ in men and $>34 \mathrm{U} / \mathrm{L}$ in women, AST level $>35 \mathrm{U} / \mathrm{L}$ in men and $>31 \mathrm{U} / \mathrm{L}$ in women, GGT level $>55 \mathrm{U} / \mathrm{L}$ in men and $>38 \mathrm{U} / \mathrm{L}$ in women ${ }^{40}$ and ALP level $>129 \mathrm{U} / \mathrm{L}$ in men and $>104 \mathrm{U} / \mathrm{L}$ in women ${ }^{41}$. Hypertension was defined as sustained high blood pressure ( $\mathrm{SBP} \geq 140 \mathrm{~mm} \mathrm{Hg}$ and/or $\mathrm{DBP} \geq 90 \mathrm{~mm} \mathrm{Hg}$ ) or the participants intake of anti-hypertensive medications. Diabetes was confirmed if the $\mathrm{FGB} \geq 126 \mathrm{mg} / \mathrm{dL}$, and/or with a history of usage of hypoglycemic agents and/ or insulin ${ }^{42}$. Smoking status was defined as present smokers or non/ex-smokers. Physical activity in daily life was grouped as light (moderate housework or comfortable office jobs), moderate (swimming and walking) and heavy (jogging, lifting, carrying, or sports) ${ }^{38}$.

Statistical analysis. The data were analyzed statistically using the software IBM SPSS Statistics version 23. Data are presented as means \pm SD or, $\%$. An independent sample $t$-test was used to compare the variables between the gender groups. The Chi-square test was applied to compare the prevalence of dyslipidemia and elevated liver 


\begin{tabular}{|c|c|c|c|c|}
\hline Variables & Male $(n=318)$ & Female $(\mathbf{n}=87)$ & Total $(n=405)$ & $P$-value \\
\hline Age (years) & $40.5 \pm 12.7$ & $40.6 \pm 13.4$ & $40.5 \pm 12.9$ & 0.959 \\
\hline Weight (kg) & $67.1 \pm 10.7$ & $58.3 \pm 9.7$ & $65.2 \pm 11.1$ & $<0.001$ \\
\hline Height (cm) & $165.4 \pm 6.8$ & $152.7 \pm 7.9$ & $162.7 \pm 8.7$ & $<0.001$ \\
\hline BMI $\left(\mathrm{kg} / \mathrm{m}^{2}\right)$ & $24.5 \pm 3.4$ & $25.1 \pm 4.1$ & $24.6 \pm 3.5$ & 0.180 \\
\hline $\mathrm{WC}(\mathrm{cm})$ & $86.0 \pm 12.1$ & $85.7 \pm 10.9$ & $85.9 \pm 11.8$ & 0.841 \\
\hline $\mathrm{HC}(\mathrm{cm})$ & $92.1 \pm 8.2$ & $92.5 \pm 8.9$ & $92.2 \pm 8.4$ & 0.741 \\
\hline SBP (mmHg) & $126.9 \pm 14.5$ & $126.2 \pm 18.8$ & $126.7 \pm 15.5$ & 0.716 \\
\hline DBP (mmHg) & $83.6 \pm 9.9$ & $83.2 \pm 10.1$ & $83.5 \pm 9.9$ & 0.739 \\
\hline PP (beats/min) & $76.4 \pm 12.5$ & $82.3 \pm 12.1$ & $77.7 \pm 12.6$ & $<0.001$ \\
\hline Glucose $(\mathrm{mg} / \mathrm{dL})$ & $118.8 \pm 59.4$ & $136.8 \pm 70.2$ & $122.4 \pm 63.0$ & 0.014 \\
\hline $\mathrm{TG}(\mathrm{mg} / \mathrm{dL})$ & $194.6 \pm 112.4$ & $153.2 \pm 94.6$ & $185.7 \pm 110.0$ & 0.001 \\
\hline $\mathrm{TC}(\mathrm{mg} / \mathrm{dL})$ & $203.3 \pm 73.4$ & $228.3 \pm 92.0$ & $208.7 \pm 78.3$ & 0.021 \\
\hline $\mathrm{LDL}(\mathrm{mg} / \mathrm{dL})$ & $133.6 \pm 62.3$ & $162.7 \pm 89.8$ & $139.9 \pm 70.0$ & 0.001 \\
\hline HDL (mg/dL) & $32.8 \pm 13.3$ & $35.9 \pm 9.7$ & $33.4 \pm 12.6$ & 0.016 \\
\hline $\operatorname{ALT}(\mathrm{U} / \mathrm{L})$ & $34.5 \pm 17.2$ & $31.7 \pm 25.8$ & $33.9 \pm 19.4$ & 0.350 \\
\hline AST (U/L) & $27.0 \pm 12.0$ & $29.0 \pm 17.1$ & $27.4 \pm 13.4$ & 0.404 \\
\hline GGT (U/L) & $32.8 \pm 30.2$ & $29.6 \pm 28.2$ & $32.1 \pm 29.8$ & 0.380 \\
\hline $\operatorname{ALP}(\mathrm{U} / \mathrm{L})$ & $100.6 \pm 40.3$ & $87.9 \pm 35.0$ & $97.6 \pm 39.5$ & 0.023 \\
\hline Hypertensive (\%) & 41.6 & 46.0 & 42.6 & 0.470 \\
\hline Diabetic (\%) & 29.9 & 49.4 & 34.1 & 0.001 \\
\hline \multicolumn{5}{|c|}{ Physical activity (\%) } \\
\hline Low & 20.1 & 26.2 & 21.6 & \multirow{3}{*}{0.335} \\
\hline Medium & 69.8 & 68.9 & 69.6 & \\
\hline Adequate & 10.1 & 4.9 & 8.8 & \\
\hline \multicolumn{5}{|c|}{ Smoking status (\%) } \\
\hline No & 70.8 & 100 & 77 & \multirow{2}{*}{$<0.001$} \\
\hline Yes & 29.2 & 0 & 23 & \\
\hline
\end{tabular}

Table 1. Baseline characteristics of the study participants. Data are presented as mean \pm SD or $\%$. $P$-values are obtained from independent sample t-test or Chi-square test.

enzymes in different groups. The relationship between lipid profile markers and liver enzymes was evaluated using multivariate logistic regression models. The $p$-value $<0.05$ was considered statistically significant.

\section{Results}

Baseline characteristics in the sex groups. Baseline characteristics of enrolled participants are shown in Table 1. Among the 405 respondents, 318 were males and 87 were female subjects. The mean age of the total participants was $40.5 \pm 12.9$ years (men, $40.5 \pm 12.7$ years and female, $40.6 \pm 13.4$ years). There was a significant difference in the mean level of serum TC, TG, LDL-C, HDL-C, FBG and ALP $(p<0.05$ for all cases) in the male and female groups. However, no significant difference was observed for BMI, WC, HC, SBP, DBP, ALT, AST and GGT in the gender groups. The prevalence of hypertension and diabetes was higher in females $(46 \%$ and $49.4 \%$, respectively) than in the male participants ( $41.6 \%$ and $29.9 \%$, respectively). Regarding smoking status, about $29 \%$ of the male participants were habituated with smoking, whereas, all of the female participants were non-smokers.

Prevalence of dyslipidemia and liver enzymes abnormalities in the sex group. The prevalence of dyslipidemia and elevated liver enzymes in the sex group is depicted in Fig. 1. Overall, the prevalence of elevated TG, TC, LDL and low HDL was $30.9 \%, 23.7 \%, 26.2 \%$ and $78.8 \%$, respectively, in the sex group. Male participants had a high prevalence of elevated TG levels and low HDL levels, whereas, female participants had an increased prevalence of elevated TC and LDL levels. On the other hand, the overall prevalence of elevated ALT, AST, GGT and ALP were $18.8 \%, 21.6 \%, 12.9 \%$ and $21.9 \%$, respectively. Female participants had a comparatively high prevalence of elevated liver enzymes especially AST, GGT and ALP.

Prevalence of dyslipidemia and liver dysfunction in different groups. The prevalence of elevation and the mean level of lipid markers and liver enzymes in different health status groups are summarized in Table 2. The levels and prevalence of elevated lipid markers and hepatic enzymes were higher in hypertensive and diabetic groups compared to the healthy control group.

Prevalence of abnormal liver enzymes in dyslipidemic adults. About $61 \%$ of participants with dyslipidemia (having one or more elevated lipid levels) had at least one or more elevated levels of liver enzymes 

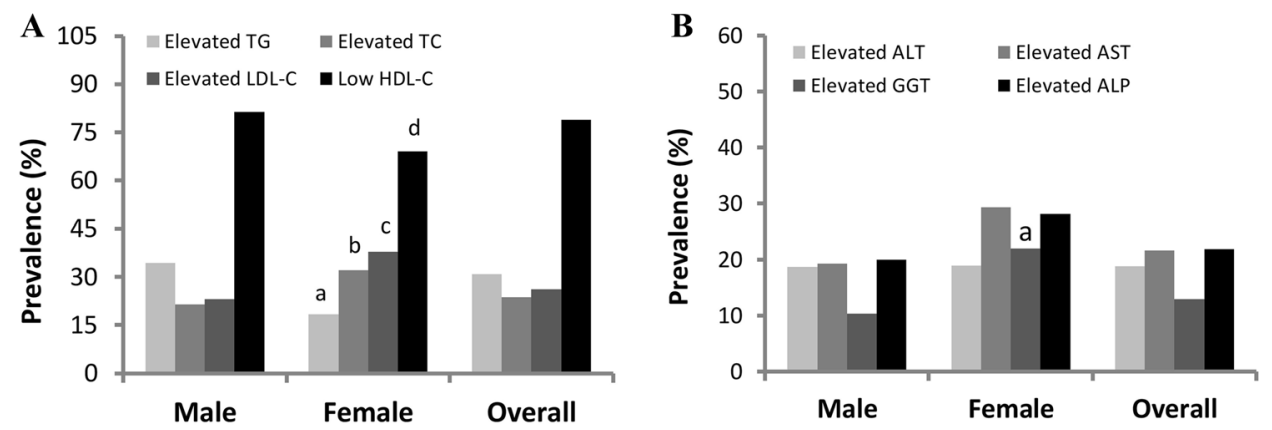

Figure 1. Prevalence of dyslipidemia (A) and elevated liver enzymes (B) in the gender group. In (A) ${ }^{\mathrm{a}, \mathrm{c}} p<0.05$; ${ }^{\mathrm{b}, \mathrm{d}} p<0.01$ when the prevalence is compared to the male group. In $(\mathbf{B}){ }^{\mathrm{a}} p<0.01$ when the prevalence is compared to male group. $P$-values are obtained from Chi Square test.

\begin{tabular}{|c|c|c|c|c|c|c|}
\hline Variables & Overall $(n=405)$ & Healthy $(n=176)$ & Hypertensive $(n=172)$ & $P$-value ${ }^{\text {a }}$ & Diabetic $(n=138)$ & $P$-value ${ }^{\mathrm{b}}$ \\
\hline $\mathrm{TG}(\mathrm{mg} / \mathrm{dL})$ & $185.7 \pm 110.0$ & $163.6 \pm 95.1$ & $200.3 \pm 116.3$ & 0.005 & $211.0 \pm 127.4$ & 0.001 \\
\hline Elevated TG, n (\%) & $125(30.9)$ & $39(22.3)$ & $61(35.5)$ & 0.021 & $56(40.6)$ & 0.001 \\
\hline $\mathrm{TC}(\mathrm{mg} / \mathrm{dL})$ & $208.7 \pm 78.3$ & $183.5 \pm 52.0$ & $230.4 \pm 91.5$ & $<0.001$ & $235.7 \pm 101.9$ & $<0.001$ \\
\hline Elevated TC, n (\%) & $96(23.7)$ & $17(9.7)$ & $58(33.7)$ & $<0.001$ & $51(37)$ & $<0.001$ \\
\hline $\mathrm{LDL}(\mathrm{mg} / \mathrm{dL})$ & $139.9 \pm 70.0$ & $120.4 \pm 46.9$ & $157.1 \pm 80.9$ & $<0.001$ & $159.9 \pm 94.9$ & $<0.001$ \\
\hline Elevated LDL, n (\%) & $106(26.2)$ & $27(15.3)$ & $61(35.5)$ & $<0.001$ & $49(35.5)$ & $<0.001$ \\
\hline $\mathrm{HDL}(\mathrm{mg} / \mathrm{dL})$ & $33.4 \pm 12.6$ & $31.0 \pm 9.0$ & $35.3 \pm 14.4$ & 0.002 & $36.6 \pm 16.4$ & $<0.001$ \\
\hline Low HDL, n (\%) & $319(78.8)$ & $150(85.2)$ & $128(74.4)$ & 0.010 & $95(68.8)$ & 0.001 \\
\hline $\operatorname{ALT}(\mathrm{U} / \mathrm{L})$ & $33.9 \pm 19.4$ & $30.6 \pm 14.5$ & $36.6 \pm 23.0$ & 0.014 & $36.7 \pm 22.2$ & 0.006 \\
\hline Elevated ALT, n (\%) & $75(18.8)$ & $27(15.3)$ & $37(22)$ & 0.146 & $33(25)$ & 0.039 \\
\hline AST (U/L) & $27.4 \pm 13.4$ & $23.7 \pm 10.9$ & $30.5 \pm 15.7$ & 0.003 & $32.2 \pm 15.2$ & $<0.001$ \\
\hline Elevated AST, n (\%) & $53(21.6)$ & $17(15.2)$ & $25(26.3)$ & 0.162 & $28(28.9)$ & 0.043 \\
\hline GGT (U/L) & $32.1 \pm 29.8$ & $22.6 \pm 13.2$ & $41.0 \pm 37.3$ & $<0.001$ & $44.2 \pm 39.8$ & $<0.001$ \\
\hline Elevated GGT, n (\%) & $50(12.9)$ & $6(3.6)$ & $36(21.7)$ & $<0.001$ & $35(26)$ & $<0.001$ \\
\hline $\operatorname{ALP}(\mathrm{U} / \mathrm{L})$ & $97.9 \pm 39.5$ & $93.5 \pm 30.5$ & $100.3 \pm 41.0$ & 0.505 & $103.3 \pm 47.8$ & 0.150 \\
\hline Elevated ALP, n (\%) & $53(21.9)$ & $16(14.5)$ & $24(25.8)$ & 0.162 & $32(33.3)$ & 0.004 \\
\hline
\end{tabular}

Table 2. Prevalence of elevation and levels of lipid markers and liver enzymes in various groups. Data are presented as mean $\pm \mathrm{SD}$ or $\%$. $P$ value $\mathrm{e}^{\mathrm{a}}$ is the difference between healthy and hypertensive group and $P$ value ${ }^{\mathrm{b}}$ is the difference between healthy and diabetic group. $P$ values for mean concentrations are derived from the independent sample t-test. $P$ values for prevalence (\%) are obtained from Chi-square test.

\begin{tabular}{|c|c|c|c|c|c|c|c|c|c|c|c|c|}
\hline \multirow[b]{2}{*}{ Variables } & \multicolumn{3}{|l|}{ TG } & \multicolumn{3}{|l|}{ TC } & \multicolumn{3}{|l|}{ LDL } & \multicolumn{3}{|l|}{ HDL } \\
\hline & Normal & Elevated & $P$-value & Normal & Elevated & $P$-value & Normal & Elevated & $P$-value & Normal & Low & $P$-value \\
\hline Elevated ALT & 15.6 & 25.2 & 0.023 & 16.8 & 25.3 & 0.065 & 18.7 & 19.0 & 0.939 & 20.5 & 18.4 & 0.659 \\
\hline Elevated AST & 20.1 & 25.0 & 0.391 & 16.4 & 32.5 & 0.004 & 17.5 & 30.4 & 0.022 & 20.3 & 22.0 & 0.782 \\
\hline Elevated GGT & 9.8 & 19.7 & 0.007 & 9.1 & 24.7 & $<0.001$ & 11.5 & 16.5 & 0.197 & 15.4 & 12.2 & 0.455 \\
\hline Elevated ALP & 18.5 & 29.7 & 0.051 & 18.0 & \begin{tabular}{|l|}
30.7 \\
\end{tabular} & 0.027 & 19.2 & 28.0 & 0.124 & 16.4 & 23.5 & 0.259 \\
\hline
\end{tabular}

Table 3. Prevalence of elevated liver enzymes in dyslipidemic adults. Data are expressed as percentage (\%). $P$-values are obtained from Chi-Square test.

(Table 3). These abnormalities were significantly higher in individuals with elevated TC (except elevated ALT) and elevated TG (except elevated AST and ALP) than in individuals with normal TG and TC level (at least $p<0.05$ for all cases). Similarly, the subjects having elevated LDL levels had significantly high levels of AST compared to the subjects having normal LDL concentrations $(p<0.05)$.

Association between lipid markers and liver enzymes. In all regression models, serum TG showed a significant positive association with all liver enzymes (at least $p<0.05$ for all cases) (Table 4). A similar associa- 


\begin{tabular}{|c|c|c|c|c|c|c|c|c|}
\hline & \multicolumn{2}{|l|}{ ALT } & \multicolumn{2}{|l|}{ AST } & \multicolumn{2}{|l|}{ GGT } & \multicolumn{2}{|l|}{ ALP } \\
\hline & OR $(95 \% \mathrm{CI})$ & $P$ for trend & OR (95\% CI) & $P$ for trend & OR (95\% CI) & $P$ for trend & OR $(95 \% \mathrm{CI})$ & $P$ for trend \\
\hline \multicolumn{9}{|l|}{ TG } \\
\hline Model 1 & $\begin{array}{l}1.08(1.01- \\
1.16)\end{array}$ & 0.009 & $\begin{array}{l}1.08(1.01- \\
1.13)\end{array}$ & 0.009 & $\begin{array}{l}1.11(1.08- \\
1.14)\end{array}$ & 0.006 & $\begin{array}{l}1.04(1.01- \\
1.07)\end{array}$ & 0.007 \\
\hline Model 2 & $\begin{array}{l}1.08(1.01- \\
1.16)\end{array}$ & 0.024 & $\begin{array}{l}1.08(1.01- \\
1.16)\end{array}$ & 0.024 & $\begin{array}{l}1.12(1.08- \\
1.14)\end{array}$ & 0.021 & $\begin{array}{l}1.04(1.00- \\
1.07)\end{array}$ & 0.023 \\
\hline Model 3 & $\begin{array}{l}1.10(1.22- \\
1.38)\end{array}$ & 0.023 & $\begin{array}{l}1.10(1.22- \\
1.38)\end{array}$ & 0.023 & $\begin{array}{l}1.13(1.03- \\
1.24)\end{array}$ & 0.022 & $\begin{array}{l}1.05(1.00- \\
1.09)\end{array}$ & 0.019 \\
\hline \multicolumn{9}{|l|}{ TC } \\
\hline Model 1 & $\begin{array}{l}1.06(1.01- \\
1.12)\end{array}$ & 0.007 & $\begin{array}{l}1.07(1.01- \\
1.13)\end{array}$ & 0.009 & $\begin{array}{l}1.10(1.08- \\
1.14)\end{array}$ & 0.006 & $\begin{array}{l}0.98(0.97- \\
1.00)\end{array}$ & 0.281 \\
\hline Model 2 & $\begin{array}{l}1.06(1.00- \\
1.12)\end{array}$ & 0.023 & $\begin{array}{l}1.07(1.01- \\
1.13)\end{array}$ & 0.024 & $\begin{array}{l}1.10(1.08- \\
1.14)\end{array}$ & 0.021 & $\begin{array}{l}0.98(0.96- \\
1.01)\end{array}$ & 0.211 \\
\hline Model 3 & $\begin{array}{l}1.07(1.00- \\
1.15)\end{array}$ & 0.019 & $\begin{array}{l}1.09(1.21- \\
1.37)\end{array}$ & 0.023 & $\begin{array}{l}1.11(1.03- \\
1.24)\end{array}$ & 0.022 & $\begin{array}{l}0.96(0.96- \\
1.01)\end{array}$ & 0.211 \\
\hline \multicolumn{9}{|l|}{ LDL } \\
\hline Model 1 & $\begin{array}{l}1.04(1.01- \\
1.09)\end{array}$ & 0.011 & $\begin{array}{l}1.04(0.99- \\
1.08)\end{array}$ & 0.096 & $\begin{array}{l}1.04(1.00- \\
1.07)\end{array}$ & 0.023 & $\begin{array}{l}0.99(0.98- \\
1.00)\end{array}$ & 0.279 \\
\hline Model 2 & $\begin{array}{l}1.04(1.00- \\
1.07)\end{array}$ & 0.025 & $\begin{array}{l}1.03(0.98- \\
1.08)\end{array}$ & 0.134 & $\begin{array}{l}1.05(1.00- \\
1.09)\end{array}$ & 0.019 & $\begin{array}{l}0.98(0.97- \\
1.01)\end{array}$ & 0.209 \\
\hline Model 3 & $\begin{array}{l}1.05(1.00- \\
1.09)\end{array}$ & 0.023 & $\begin{array}{l}1.05(0.99- \\
1.12)\end{array}$ & 0.119 & $\begin{array}{l}1.06(1.01- \\
1.11)\end{array}$ & 0.014 & $\begin{array}{l}0.99(0.97- \\
1.00)\end{array}$ & 0.209 \\
\hline \multicolumn{9}{|l|}{ HDL } \\
\hline Model 1 & $\begin{array}{l}0.99(0.98- \\
1.00)\end{array}$ & 0.279 & $\begin{array}{l}0.94(0.97- \\
1.00)\end{array}$ & 0.284 & $\begin{array}{l}-1.04 \\
(1.01-1.07)\end{array}$ & 0.007 & $\begin{array}{l}-0.99 \\
(0.98-1.00)\end{array}$ & 0.279 \\
\hline Model 2 & $\begin{array}{l}0.98(0.97- \\
1.01)\end{array}$ & 0.209 & $\begin{array}{l}0.95(0.98- \\
1.01)\end{array}$ & 0.212 & $\begin{array}{l}-1.04 \\
(1.00-1.07)\end{array}$ & 0.023 & $\begin{array}{l}-0.98 \\
(0.97-1.01)\end{array}$ & 0.209 \\
\hline Model 3 & $\begin{array}{l}0.99(0.97- \\
1.00)\end{array}$ & 0.209 & $\begin{array}{l}0.93(0.96- \\
1.00)\end{array}$ & 0.212 & $\begin{array}{l}-1.05 \\
(1.00-1.09)\end{array}$ & 0.019 & $\begin{array}{l}-0.99 \\
(0.97-1.00)\end{array}$ & 0.209 \\
\hline
\end{tabular}

Table 4. Association between lipid markers and liver enzymes. Multivariate logistic regression was applied to evaluate the relationship between lipid profile markers and liver enzymes. Lipid profile markers were dependent variable and liver enzymes were independent variables. Three models were applied in the regression analysis. Adjusted covariates: model $1=$ age, sex; model $2=$ model $1+$ BMI, WC and FBG; model $3=$ model $2+$ SBP and DBP and physical activity.

tion was found for TC with ALT, AST and GGT, and for LDL with ALT and GGT (at least $p<0.05$ for all cases). HDL showed a significant negative association only with GGT ( $p<0.01$ for model 1 and $p<0.05$ for model 2-3).

\section{Discussion}

In the present study, a high prevalence of dyslipidemia was found among the study subjects. Of the liver enzymes, serum GGT showed an independent association with all lipid markers. To our knowledge, this is the first report on the association between lipid profile markers and liver enzymes for the Bangladeshi population.

Of the total participants, approximately $88 \%$ of subjects had at least one or more elevated lipid levels. The prevalence of dyslipidemia among Bangladeshi adults has been reported in some previous studies in the range of $20.9-75.6 \%{ }^{25-27,43}$. The variations in the prevalence might be associated with the differences in the study population, study areas, socioeconomic status, age groups, genetic predisposition, and individual lifestyle as well as use of different cut-off values in determining dyslipidemia among the study population. Several studies suggest that abnormality in lipid profile is clinically associated with diabetes and hypertension ${ }^{44,45}$. Since a significant portion of our study subjects were hypertensive (42.6\%) and diabetic $(34.1 \%)$, which may be a possible underlying factor fueling the higher prevalence of dyslipidemia.

In the present study, the prevalence of low HDL was $78.8 \%$ which is in line with previous studies, where HDL cholesterol was the most commonly affected lipid parameter ${ }^{25-27}$. Some studies demonstrated that Asian people may have greater problems of low HDL cholesterol rather than other elevated lipid levels ${ }^{26,46,47}$.

In the sex group, a variation in the level of elevated lipids and liver enzymes was found in male and female participants. The levels of serum TG and low HDL were significantly higher in males compared to the females, whereas more female participants had an elevated TC and LDL compared to males. Industrialization and urbanization are increasing in Bangladesh at the same pace as many other countries of the world. A previous study claimed that urbanization is one of the reasons for increased dyslipidemia in Bangladesh ${ }^{48}$. However, in a separate analysis (data are not presented), we did not find any significant relationship between the degree of urbanization and dyslipidemia prevalence in our study subjects. Instead, we observed that dyslipidemia was more frequent among rural people; this might be for several reasons. For example, rural people are less aware of dyslipidemia and get limited health facilities compared to urban people. Poor and unhealthy diet and inadequate health 
knowledge among the rural people would be significant contributing factors to dyslipidemia. A more detailed investigation is needed to confirm this assumption.

The prevalence of both dyslipidemia and liver enzyme abnormalities was higher in hypertensive and diabetic groups compared to the healthy control group. These abnormalities were even more frequent among the participants who were hypertensive-diabetic. Such findings indicate that diabetes and hypertension can significantly contribute to the burden of dyslipidemia and hepatic dysfunctions. The prevalence of dyslipidemia and liver functions test markers was also found in some previous studies ${ }^{44,45,49-51}$. In our study, a very high predominance of elevated liver enzymes was found among participants who were dyslipidemic. This finding is partly consistent with a study in other populations, where abnormal liver function test markers were firmly identified in dyslipidemic individuals, which likely mirrored the presence of dyslipidemia in cases associated with NAFLD ${ }^{52}$.

In regression analysis, an independent association was found between serum GGT and all lipid components. This finding supports the claims that alterations in hepatic lipid levels can contribute to liver dysfunction. Our results and available studies suggest a crucial role of GGT in the exposition of hepatic pathology related to dyslipidemia. Liver injury in hepatic enzymes concentrations can also be caused by alcohol consumption ${ }^{53}$. Due to religious restriction, alcoholic drinks consumption is very uncommon in the Bangladeshi population except in rare cases. Therefore, there is less chance to have alcoholic effects on liver enzyme levels in our study subjects.

High levels of TG, TC, LDL and low HDL have been suggested to be related to NAFLD and individuals with dyslipidemia are at higher risk of developing fatty liver disease. The exact reasons for NAFLD pathogenesis are not clear yet, although it is suggested that, elevated liver function test markers are indicative of excess fat deposition in the liver and continuous assault by lipids on the liver while it exerts regular liver functions adds more workload on hepatic cells and thereby could change its physiology. Most importantly the deposited lipid particles could foster inflammation of liver tissue with the production of free radicals inside ${ }^{54}$. These free radicals then cause fibrosis or cell death of the liver tissue. The damaged hepatic cell can release more hepatic enzymes outside and can become more permeable because of thinning from the extra stretch due to deposited lipid remnants. Again, it has been suggested that cellular GGT may be associated with the generation of reactive oxygen species $^{55}$, which may indicate the compromised antioxidant capacity of the liver due to the elevated lipid levels. However, the underlying mechanism of liver enzyme abnormalities in dyslipidemia remains unclear and requires further investigations.

The major strength of our study was providing information on the prevalence of abnormal lipid markers and liver enzymes panel among hypertensive and diabetic individuals. In addition, our study is the first that evaluated the relationship between lipid profile markers and liver enzymes in Bangladeshi adults. However, there are some limitations to this study. First, the cross-sectional nature of the data may affect the relationship between lipid profile markers and liver enzymes. Secondly, we considered subject's self-reported information for a few variable measures such as level of physical activity. Moreover, the sample size was relatively small and the study was conducted in a divisional region of Bangladesh, thus our findings may not be nationally representative. However, our findings may be worth reference to future studies.

\section{Conclusions}

A high prevalence of dyslipidemia and liver enzyme abnormalities was observed among the Bangladeshi adults; higher in diabetic and hypertensive subjects than in the healthy subjects. A higher frequency of elevated liver enzymes was observed in subjects with dyslipidemia. Of the four liver enzymes, only serum GGT showed the strongest relationship with the lipid profile markers. The elevated level of lipids and GGT in the blood may be a better indicator to monitor the progression and severity of lipid-induced hepatic dysfunctions and associated complications. This study finding indicates that dyslipidemic individuals may have a higher chance of developing liver disease than non-dyslipidemic individuals. A large-scale prospective study is needed to understand the underlying mechanisms of lipid-induced hepatic dysfunction in the Bangladeshi population.

Received: 31 July 2021; Accepted: 14 January 2022

Published online: 02 February 2022

\section{References}

1. Ciffone, N. A. \& Copple, T. Managing dyslipidemia for CVD prevention: A review of recent clinical practice guidelines. Nurse Pract. 44, 8-16 (2019).

2. Pirillo, A., Casula, M., Olmastroni, E., Norata, G. D. \& Catapano, A. L. Global epidemiology of dyslipidaemias. Nat. Rev. Cardiol 18, 689-700 (2021).

3. Farzadfar, F., Finucane, M., Danaei, G. \& Pelizzari, P. M. National, regional, and global trends in serum total cholesterol since 1980: Systematic analysis of health examination surveys and epidemiological studies with 321 country-years and 3.0 million participants. Lancet 377, 578-586 (2011).

4. Htet, A. S. et al. Lipid profiles and determinants of total cholesterol and hypercholesterolaemia among 25-74 year-old urban and rural citizens of the Yangon Region, Myanmar: A cross-sectional study. BMJ Open 7, 1-8 (2017).

5. Joshi, S. R. et al. Prevalence of dyslipidemia in urban and rural India: The ICMR-INDIAB study. PLoS ONE 9, e96808 (2014).

6. Zhang, F. L. et al. The prevalence, awareness, treatment, and control of dyslipidemia in northeast China: A population-based cross-sectional survey. Lipids Health Dis. 16, 1-13 (2017).

7. Stamler, J. Established major coronary risk factors: Historical overview. Marmot M. Elliot P. Eds. Coronary Heart Disease Epidemiology: From Aetiology to Public Health 2, 18-31 (2005).

8. WHO. World Health Organization Noncommunicable Diseases Country Profiles. WHO Library Cataloguing-in-Publication Data, Geneva, Switzerland 7 (2018).

9. World Health Organization. Cardiovascular diseases (CVDs) fact sheet. World Health Organization (2017).

10. Badimon, L. \& Vilahur, G. LDL-cholesterol versus HDL-cholesterol in the atherosclerotic plaque: Inflammatory resolution versus thrombotic chaos. Ann. N. Y. Acad. Sci. 1254, 18-32 (2012). 
11. Najeeb, Q., Sameer, A. S., Aziz, R. \& Hamid, S. Association of lipid profile and liver enzymes among non-alcoholic fatty liver disease patients attending a tertiary care hospital in northern indian. Int. J. Curr. Res. 7, 14348-14352 (2015).

12. Ahmed, M. Non-alcoholic fatty liver disease in 2015. World J. Hepatol. 7, 1450 (2015).

13. Ge, X., Zheng, L., Wang, M., Du, Y. \& Jiang, J. Prevalence trends in non-alcoholic fatty liver disease at the global, regional and national levels, 1990-2017: A population-based observational study. BMJ Open 10, e036663 (2020).

14. Ray, K. NAFLD-the next global epidemic. Nat. Rev. Gastroenterol. Hepatol. 10, 621 (2013).

15. Alam, S. et al. Prevalence and risk factors of non-alcoholic fatty liver disease in Bangladesh. JGH Open 2, 39-46 (2018).

16. Hanigan, M. H. \& Henry, E. Immunohistochemical detection of y-glutamyl transpeptidase in normal human tissue. J. Histochem. Cytochem. 44, 1101-1108 (1996).

17. Whitfield, J. B. Gamma glutamyl transferase. Crit. Rev. Clin. Lab. Sci. 38, 263-355 (2001).

18. Giannini, E. G., Testa, R. \& Savarino, V. Liver enzyme alteration: A guide for clinicians. CMAJ 172, 367-379 (2005).

19. Islam, S. et al. Prevalence of elevated liver enzymes and its association with type 2 diabetes: A cross-sectional study in Bangladeshi adults. Endocrinol. Diabetes Metab 3, e00116 (2020).

20. Kim, D.-J. et al. Serum $\gamma$-glutamyltransferase within its normal concentration range is related to the presence of diabetes and cardiovascular risk factors. Diabet. Med. 22, 1134-1140 (2005).

21. Lee, D.-H. \& Jacobs, D. R. Jr. Association between serum gamma-glutamyltransferase and C-reactive protein. Atherosclerosis 178, 327-330 (2005).

22. Sanyal, D. et al. Profile of liver enzymes in non-alcoholic fatty liver disease in patients with impaired glucose tolerance and newly detected untreated type 2 diabetes. Indian J. Endocrinol. Metab 19, 597-601 (2015).

23. Nelson, R. H. Hyperlipidemia as a risk factor for cardiovascular disease. Primary Care: Clin. Office Pract. 40, 195-211 (2013).

24. Deb, S., Puthanveetil, P. \& Sakharkar, P. A Population-Based Cross-Sectional Study of the Association. 2018 (2018).

25. Fatema, K., Zwar, N. A., Milton, A. H., Ali, L. \& Rahman, B. Prevalence of risk factors for cardiovascular diseases in Bangladesh: A systematic review and meta-analysis. PLoS ONE 11, 1-14 (2016).

26. Islam, N. et al. Prevalence of dyslipidemia and associated factors among the sub-urban Bangladeshi population. Univ. Heart J. 8, $15-19$ (2012).

27. Mostafa Zaman, M. et al. Plasma lipids in a rural population of Bangladesh. Eur. J. Cardiovasc. Prevent. Rehab. Off. J. Eur. Soc. Cardiol. Work. Groups Epidemiol. Prevent. Cardiac Rehab. Exercise Physiol. 13, 444-448 (2006).

28. Ali, N. et al. Hypertension prevalence and influence of basal metabolic rate on blood pressure among adult students in Bangladesh. BMC Public Health 18, 58 (2017)

29. Ali, N. et al. Prevalence of hyperuricemia and the relationship between serum uric acid and obesity: A study on Bangladeshi adults. PLoS ONE 13, e0206850 (2018).

30. Ali, N. et al. The relationship between serum uric acid and lipid profile in Bangladeshi adults. BMC Cardiovasc. Disord. 19, 42 (2019).

31. Ali, N. et al. Relationship between serum uric acid and hypertension: A cross-sectional study in Bangladeshi adults. Sci. Rep. 9, 9061 (2019).

32. Ali, N. et al. Association between serum uric acid and metabolic syndrome: A cross-sectional study in Bangladeshi adults. Sci. Rep. 10, 7841 (2020).

33. Ali, N. et al. Assessment of the relationship of serum liver enzymes activity with general and abdominal obesity in an urban Bangladeshi population. Sci. Rep. 11, 6640 (2021).

34. Haque, T., Rahman, S., Islam, S., Molla, N. H. \& Ali, N. Assessment of the relationship between serum uric acid and glucose levels in healthy, prediabetic and diabetic individuals. Diabetol. Metab Syndr. 11, 49 (2019).

35. Rahman, S., Islam, S., Haque, T., Kathak, R. R. \& Ali, N. Association between serum liver enzymes and hypertension: A crosssectional study in Bangladeshi adults. BMC Cardiovasc. Disord. 20, 128 (2020).

36. Molla, N. H. et al. Assessment of the relationship between serum uric acid levels and liver enzymes activity in Bangladeshi adults. Sci. Rep. https://doi.org/10.1038/s41598-021-99623-z (2021).

37. Mou, A. D. et al. Prevalence of preeclampsia and the associated risk factors among pregnant women in Bangladesh. Sci. Rep. 11, 21339 (2021).

38. Ali, N., Sumon, A. H. \& Fariha, K. A. Assessment of the relationship of serum liver enzymes activity with general and abdominal obesity in an urban Bangladeshi population. Sci. Rep https://doi.org/10.1038/s41598-021-86216-z (2021).

39. Expert Panel on Detection, E. and T. of H. B. C. in A. Executive Summary of the Third Report (NCEP)-Adult Treatment Panel III. J. Am. Med. Associ. 285, 2486-2497 (2001).

40. Schumann, G. \& Klauke, R. New IFCC reference procedures for the determination of catalytic activity concentrations of five enzymes in serum: Preliminary upper reference limits obtained inhospitalized subjects. Clin. Chim. Acta 327, 69-79 (2003).

41. Tietz, N. W. \& Shuey, D. F. Reference intervals for alkaline phosphatase activity determined by the IFCC and AACC reference methods. Clin. Chem. 32, 1593-1594 (1986).

42. Marathe, P. H., Gao, H. X. \& Close, K. L. American diabetes association standards of medical care in diabetes 2017. J. Diabetes 9 , 320-324 (2017).

43. Ahsan, S. A. et al. Detection of ischaemic heart disease with risk factors in different categories of employees of University Grants Commission. Univ. Heart J. 5, 20-23 (2009).

44. Bhowmik, B. et al. Serum lipid profile and its association with diabetes and prediabetes in a rural bangladeshi population. Int. J. Environ. Res. Public Health 15, 1944 (2018).

45. Choudhury, K. N., Mainuddin, A. K. M., Wahiduzzaman, M. \& Islam, S. M. S. Serum lipid profile and its association with hypertension in Bangladesh. Vasc. Health Risk Manag. 10, 327-332 (2014).

46. Alshamiri, M. et al. Expert opinion on the applicability of dyslipidemia guidelines in Asia and the middle east. Int. J. Gener. Med. 11, 313-322 (2018).

47. Monwarul Islam, A. K. M. \& Majumder, A. A. S. Coronary artery disease in Bangladesh: A review. Indian Heart J. 65, 424-435 (2013).

48. Kumar Das, S. Serum lipid profile among urban and rural Bangladeshi population. J. Obes. Weight Loss Ther. 02, 8-11 (2012).

49. Atiba, A. S., Oparinde, D. P., Adeyemi, O., Jimoh, A. K. \& Adepeju, A. A. Liver enzymes and lipid profile among type 2 diabetic patients in Osogbo, By. Greener J. Med. Sci. 3, 174-178 (2013).

50. Kim, H. \& Han, M. Association between serum liver enzymes and metabolic syndrome in Korean adults. Int. J. Environ. Res. Public Health 15, 1658 (2018).

51. Hanley, A. J. G. et al. Elevations in markers of liver injury and risk of type 2 diabetes. Diabetes 53, 2623-2632 (2004).

52. de Souza, L. J. et al. Prevalence of dyslipidemia and risk factors in Campos dos Goytacazes, in the Brazilian State of Rio de Janeiro. Arq. Bras. Cardiol. 81, 257-264 (2003).

53. Lieber, C. S. Alcoholic fatty liver: Its pathogenesis and mechanism of progression to inflammation and fibrosis. in Alcohol vol. 34 9-19 (Elsevier, 2004)

54. Arauz, J., Ramos-Tovar, E. \& Muriel, P. Redox state and methods to evaluate oxidative stress in liver damage: From bench to bedside. Ann. Hepatol. 15, 160-173 (2016).

55. Lee, D.-H., Blomhoff, R. \& Jacobs, D. R. Review is serum gamma glutamyltransferase a marker of oxidative stress?. Free Radical Res. 38, 535-539 (2004). 


\section{Acknowledgements}

The authors would like to thank all participants for their active participation in the study.

\section{Author contributions}

N.A. contributed to the conception and design of the study, data interpretation and drafting of the manuscript. R.R.K. collected the samples, conducted the experiments and drafted some parts of the manuscript. A.H.S., N.H.M., M.H. and R.M. assisted in lab experiments and data analysis. H.R.T. and A. H. helped in sample and data collection. All authors contributed to manuscript revision, read and approved the submitted version.

\section{Competing interests}

The authors declare no competing interests.

\section{Additional information}

Correspondence and requests for materials should be addressed to N.A.

Reprints and permissions information is available at www.nature.com/reprints.

Publisher's note Springer Nature remains neutral with regard to jurisdictional claims in published maps and institutional affiliations.

(1) Open Access This article is licensed under a Creative Commons Attribution 4.0 International License, which permits use, sharing, adaptation, distribution and reproduction in any medium or format, as long as you give appropriate credit to the original author(s) and the source, provide a link to the Creative Commons licence, and indicate if changes were made. The images or other third party material in this article are included in the article's Creative Commons licence, unless indicated otherwise in a credit line to the material. If material is not included in the article's Creative Commons licence and your intended use is not permitted by statutory regulation or exceeds the permitted use, you will need to obtain permission directly from the copyright holder. To view a copy of this licence, visit http://creativecommons.org/licenses/by/4.0/.

(c) The Author(s) 2022 